\title{
PROBLEMS OF REPRODUCTION OF HUMAN RESOURCES TOWARDS THE FORMATION OF THE DIGITAL ECONOMY
}

\author{
Yulia Vladimirovna Vertakova*, Ekaterina Yurievna Charochkina, Evgeniy Dmitrievich Leontyev \\ Southwest State University, Russian Federation
}

The article is devoted to the problems of reproduction of human resources as the basis of the digital economy. The factors and conditions of formation of human resources in the digital economy are determined. It is established that the existing human potential is implemented inefficiently, which hinders the development of knowledge-intensive industries, the expansion of the scientific potential of the country. Such trends are very dangerous and can spread widely and cause great damage to society and the economy. The reform of the scientific and educational sphere in the context of the development of the information society is necessary, and the most effective in this direction are public investments in the diversification of production and training of the population, the close connection of production with innovation, science and education. Today it is important not only to solve the problems of reproduction of human resources, but also the problems of formation of a new factor of production for the development of digital society.

Key words: reproduction, products, humans, digitization

\section{INTRODUCTION}

Human resources traditionally serve as the basis for the formation of an effective and competitive economy for each country. Physical and spiritual abilities of a person are the driving force of the production process. As a factor of production, a person performs numerous functions that objectively can not perform any of the other factors, he acts as a set of abilities, studies the market, external and internal business conditions, determines and optimizes the structure of production, motivates labor, subordinates the activities of the organization to the goals of increasing production, increasing profitability on the basis of the formation of its competitiveness. Today, the task of reproduction of human resources is not only to fill the labor market with traditional labor force, but also to form a new labor resource, new knowledge and competencies for the digital economy. It is dangerous to develop and use digital technologies and not understand the principles on which they operate, this leads to their misuse and inefficient use, or they remain without application and cause direct losses to society and the state [1]. As a result, the study of the problem of reproduction of human resources in the digital economy is seen as the most relevant.

The new stage of development of modern society, the widespread use of information technology, modernization and digitalization of the economy impose new requirements on the person, significantly change its place and role in production and society, the priority conditions for the development of national competitiveness are not natural and financial resources, and their human professional and personal characteristics [2]. Factors and conditions of formation of human resources at the stage of formation of the digital economy are insufficiently investigated, this is evidenced, in particular, by the current state of the labor force in many areas and sectors of the econ- omy of countries, especially developing countries, whe re competitive production has not yet been created and the re is not enough professional labor resources for the deve lopment of high-tech industries and enterprises (Fig. 1).

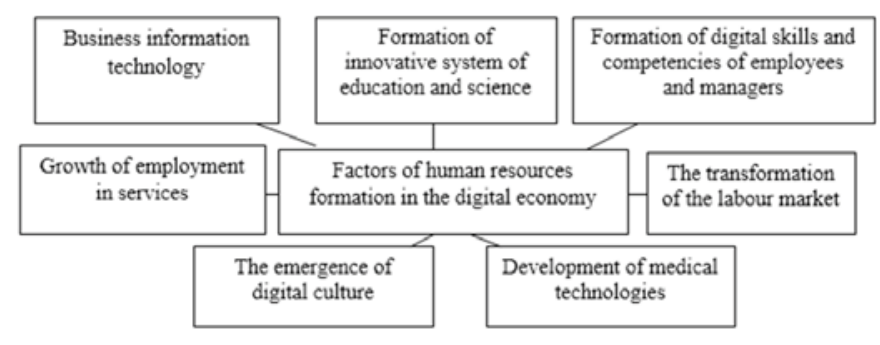

Figure 1: Factors of human resources formation in the digital economy

\section{METHODS AND MODELS}

The research was based on fundamental and applied studies of the theory and practice of human resources, their essence and problems of reproduction. On the basis of a systematic approach with the use of dialectic, economic and statistical, monographic, abstract-logical and expert-analytical methods, the main categories are identified and the main results of the research are presented.

The category of human resources is represented by a variety of different theories and approaches to the definition of their essence and structure. The traditional approach to the definition of the essence of "human resources" (from French "ressorce" - reserves, reserves) until the end of the twentieth century identified them with the category "labor resources" and defined as available people, human reserves with their professional and physical abilities to ensure the processes of social reproduction [3]. In the modern economy, accents have shifted in terms of 
enhancing the role of man in the aspect of forming the potential of the economy [4]. The answer to the question of why human resources became the center of attention of researchers can be found in the work of Manuel Castells: "Each way of developing society is determined by an element that is fundamental to increasing the productivity of the production process" [5]. Thus, at different stages of the formation of social production, the approach to defining the role and place of a person in it also changed. In the agrarian mode of production, such an element was the presence and quantity of labor and other resources. With the industrial method - this is a new energy sources, management capabilities and their concentration. In the information society, the main source of productivity lies in the technology of knowledge accumulation, information processing and symbolic communication [6]. In recent years, thanks to qualitative changes in attitudes to the role of man in the system of social production, the meaning of the concept of "human resources" is filled with new content, the accents in which are shifted towards a more complete use of all potential (and above all intellectual) human capabilities.

This approach allows us to rethink the human resource in the system of the digital economy formation. Considering a person only as a "labor force" answered mainly the needs of the industrial economy, its extensive growth. If we consider a person as part of a human resource as an aggregate of a labor resource and human potential, then a certain interdisciplinary approach becomes apparent, which makes it possible to use more fully in science and in practice all the potential possibilities of a person, first of all his intellectual and creative potentials. The basis of the latter is the level of knowledge and culture, capable of radically changing the processes of economic development in the direction of improving efficiency, quality and competitiveness based on the transformation of new knowledge into the leading productive force of modern digital society.

The digital economy places new demands on the workforce and the economically active population as a whole. The problem of reproduction of human resources in the digital economy is of paramount importance. The reproduction of human resources refers to the process of renewal, expansion and accumulation of the necessary characteristics that meet the needs of the digital economy. The interest of theory and practice in regulating the reproduction of human resources in the digital economy is determined by the fact that traditional approaches and concepts of the essence of "human resources" are no longer relevant for the analysis of innovative processes and modern phenomena in society [7]. Effective regulation of the reproduction of human resources, based on the new system, remains a little-studied and urgent problem. Until recently, these issues were reduced to improving the use of labor resources, now it is proposed to put the whole set of socio-economic factors into the basis of their solution, because human resources are not only the conditions for scientific, economic, social and envi- ronmental progress, but also the basis for the formation of a new generation of personnel for the digital economy [8]. Currently, the socio - economic situation in society has changed fundamentally-work is becoming more complex it requires not only fundamental knowledge but also skills, possession of significant both General cultural and professional competencies, but also requires the formation of a new type of innovative person, able to quickly adapt to the trends of the modern digital labor market. This approach will make it possible to master the achievements of science and digital technologies more intensively, to get rid of dependence, to use the experience of foreign specialists and scientists, to create a new structure of the labor market, to integrate them into the world economy [9]. In these conditions, the issues of choosing a modern paradigm of education development are of great importance. Models of education in developed countries are characterized by mundane specificity and priority of practical knowledge, skills and abilities, they do not have that far from practice. Multi-level education is used, which allows to differentiate education according to the complexity of work. As the practice of developed countries shows, the state should be the main source of formation and reproduction of human capital [10]. This process should permeate the entire system of its reproduction - from education and training to advanced training. It is possible to provide all this through the development of demography, education and health care.

\section{RESULTS AND DISCUSSION}

From the point of view of state regulation, an important condition for the reproduction of human resources in the digital economy is the development and modernization of the education system, as this is the main prerequisite for economic growth and improving the quality of life of the population [11]. Spending on education is a large item of the budget of any country, as spending on the formation and production of human capital determine the level of education of the population and its competitiveness on the world stage. Traditionally, developed countries spend an order of magnitude more on education than developing countries, although in the last few years the situation has begun to change in favor of some developing countries (Table 1).

So today the main task of the state should be to provide the population of the country with affordable and high-quality health care, in kindergartens and schools to develop the promotion of healthy lifestyles, the development of medical technologies. According to the rating of countries with the most effective health care system, Russia ranks 53rd, losing the position of Brazil, the Republic of Belarus, Kazakhstan. The ranking is based on total health expenditure as \% of GDP per capita and life expectancy, with the highest score given to the country with the highest life expectancy and the lowest health financing. Currently, according to Bloomberg, the leaders among the countries with the most effective health care are: Hong Kong, Singapore, Spain, South Korea (Table 2). 
This situation suggests that the sphere of reproduction of human capital is experiencing a serious systemic crisis, today it needs a new paradigm, it can not perform the traditional functions. The reason for these phenomena should be seen in the crisis of economy, Finance, ecology, social and institutional relations, in the inadequacy of social policy to the needs of the information society. First, this is reflected in the lack of resources, backward technologies, and inadequate skills.

The conditions of reproduction of human capital at the present stage are the processes of Informatization and globalization of all spheres of activity. These conditions

Table 1: Expenditure on education as \% of GDP in some countries in 2017

\begin{tabular}{|l|c|}
\hline Country & $\begin{array}{l}\text { Expenditure on education, } \\
\% \text { of GDP }\end{array}$ \\
\hline Sweden & 5,2 \\
\hline Britain & 4,8 \\
\hline France & 4,8 \\
\hline Republic of Korea & 4,6 \\
\hline Canada & 4,5 \\
\hline USA & 4,2 \\
\hline Germany & 3,7 \\
\hline Russia & 3,6 \\
\hline Japan & 3,2 \\
\hline
\end{tabular}

Source: Education in figures 2018 [Electronic resource]. Available at: https://www.hse.ru/primarydata/oc2018

Table 2: Ranking of countries with the most effective health care system in 2017

\begin{tabular}{|c|c|c|c|c|}
\hline 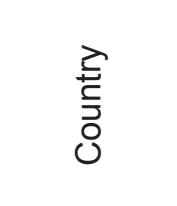 & 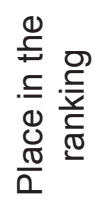 & 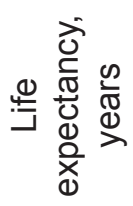 & 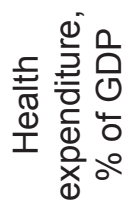 & 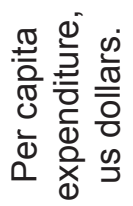 \\
\hline $\begin{array}{l}\text { Hong } \\
\text { Kong }\end{array}$ & 1 & 84,3 & 5,7 & 2222 \\
\hline Singapore & 2 & 82,7 & 4,3 & 2280 \\
\hline Spain & 3 & 82,8 & 9,2 & 2354 \\
\hline Italy & 4 & 82,5 & 9,0 & 2700 \\
\hline $\begin{array}{l}\text { South } \\
\text { Korea }\end{array}$ & 5 & 82,0 & 7,4 & 2013 \\
\hline Japan & 6 & 83,8 & 10,9 & 3733 \\
\hline Russia & 53 & 71,2 & 5,6 & 524 \\
\hline
\end{tabular}

Source: these are the economies with the most (and least) effective health care [E-resource]. Available at: https://www.bloomberg.com/ news/articles/2018-09-19/u-s-near-bottom-of-health-index-hong-kongand-singapore-at-top form a new concept of public policy, and therefore a new concept of an innovative person who must comply with the changes, actively participate in the generation of new ideas and digital technologies. In this case, the most effective public investment in the diversification of production and training of the population, the close connection of production with innovation, science and education [12]. It is not enough just to train young people in it technologies, it is necessary to provide jobs, otherwise education will be unclaimed, which will lead to brain drain. To do this, the state needs an effective strategy, optimal institutional conditions for the capitalization of knowledge and skills. For investment in human capital to lead to an increase in value added in the economy, a qualitatively different economic and political environment is needed. What is urgently needed is a flexible mechanism to ensure interaction between the labour market and educational institutions, through which the quality of human resources in the country can be directly affected. The system of research activities also needs to be reformed. The main task of this sphere is to stimulate to the maximum extent the intensification of research work, increase its efficiency through the integration of science with innovative business, education and digital culture. The idea of integrating science with education and production in a broad sense became widespread in the conditions of the scientific and technical revolution in the 50-60 years of the XX century [13]. In recent decades, much has been done in this regard, the world science, innovation, education is rapidly developing, but to the organic integration of these areas is still far, science, education and business, often develop apart from each other, do not form a single synchronous mechanism. Research and production clusters are also promising. It is necessary to improve the financial relationship between science and production, scientific products should be properly paid, be in demand. Significant changes are to be made in the development of education, it should be sectoral, closely related to the needs of high-tech sectors of the economy, not only in quantity but also in quality [14]. It is equally important to create a system of organizational and financial instruments of interaction with science and education in the market. Even small contributions from the sold products to the Federal and regional funds for the development of science and education could make their ties even closer, contribute to the creation of flexible forms of interaction: the organization of student and postgraduate, scientific and industrial practices of students, contracts for the implementation of projects with innovative technologies [15]. The success of their interaction, as world practice shows, is often provided not by large scientific institutions, but by the organization of small, mobile departments, departments, design bureaus, working closely and efficiently with production [16]. Countries with a developed digital economy are actively transforming their educational systems and approaches to learning, primarily by assisting in the adaptation of the population to new conditions, attracting 
the best specialists in the field of education and making the most of the opportunities of digitalization in scientific activities. The concept of innovative development of Russia in this regard opens up great prospects.

\section{CONCLUSION}

Now it is important that the tasks set by the state in terms of the development of human resources in the field of science, education, technology and innovation are implemented. It is important to ensure the readiness of science and education to new realities, to create prerequisites for updating approaches to learning, using existing trends. Reproduction of human resources is an ongoing process, as a result of which a person increases and increases his potential. And such areas as education, science and health care together are involved in the formation of human resources. Overcoming the problems of reproduction of human resources today is a priority task of the state, the solution of which will significantly accelerate the formation of an effective digital economy.

\section{ACKNOWLEDGEMENT}

The reported study was funded by RFBR according to the research project № 18-010-01119 «Management of digital transformation of innovation-industrial cluster as a system-forming element of the industrial digital platform: methodology, tools, practice».

\section{REFERENCES}

1. Kuladzhi T., Babkin A., Murtazaev S.A. (2018). Matrix Tool for Efficiency Assessment of Production of Building Materials and Constructions in the Digital Economy. Murgul V., Popovic Z., International Scientific Conference Energy Management of Municipal Transportation Facilities and Transport EMMFT 2017. EMMFT 2017. Advances in Intelligent Systems and Computing, 692. Springer, Cham.

2. Becker, G. (1975). Human Capital: A Theoretical and Empirical Analysis, with Special Reference to Education, Second Edition, New York: Columbia University Press for NBER.

3. Stigler, G.J. (1961). The Economics of Information. Journal of Political Economy, 69. 213-213. doi: 10.1086/258464.

4. Armstrong, M., Taylor, S. (2014). Armstrong's handbook of human resource management practice, Philadelphia, PA : Kogan Page Ltd.

5. Castells, M. (2010). The Information Age: Economy, Society and Culture Volume 1: The Rise of the Network Society, 2nd ed. Oxford: Wiley Blackwell.

6. Machlup. F. (1973). The Production and Distribution of Knowledge in the United States, USA, Princeton University Press.

7. Gabdullin, N. M. (2018). Modern approaches and methods of measuring human capital. Questions of innovation economy, 8(4), pp. 785-798.
8. Thomas, J. C. (2002). Human capital in the information age. Canadian Public Policy, 28(1), pp. 73-80. Available at: http://www.jstor.org/stable/3552161

9. Crawford, R. (1991). In the era of human capital. New York: HarperBusiness, 197 p.

10. Pelikhov, N. I., Kushnikov, E. I. (2018). On the question of factors of production in the modern economy. Creative economy, 12(11), pp. 1759-1770.

11. Fedorova, O. I., Zueva, E. G. (2018). Accumulation and realization of human capital in new conditions: opportunities and limitations. Creative economy, 12(10), pp. 1649-1660.

12. Coleman, J. (1990). Fundamentals of social theory. Belknap Press of Harvard University Press, pp. 241527.

13. Nureyev, R. M. (2005). Development theories: new models of economic growth (contribution of human capital). Economic Issues, 9, p. 345.

14. Gvozdeva, E. U., Sterzer, T. A. (2007). Human capital as a factor of Russia's development. ECO, 7, pp. 123-133.

15. Vertakova Y., Klevtsova, M., Babich. T. (2016). Identification of the new research areas and development of the existing ones by methods of morphological analysis and synthesis. Economic Annals-XXI, 157, pp. 4-8.

16. Plotnikov V.A., Vertakova Yu.V. (2015). Sustainable development of spatially distributed socio-economic system: the experience of Russia. Innovation Management and Sustainable Economic Competitive Advantage: From Regional Development to Global Growth, IBIMA 2015 Proceedings of the 26th International Business Information Management Association Conference, pp. 3224-3229.

Paper submitted: 11.06.2019.

Paper accepted: 18.09.2019.

This is an open access article distributed under the CC BY-NC-ND 4.0 terms and conditions. 